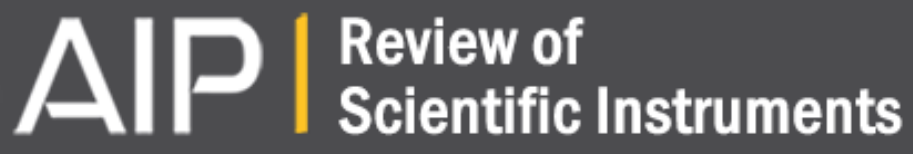

Design of a new reactor-like high temperature near ambient pressure scanning tunneling microscope for catalysis studies

Franklin (Feng) Tao, Luan Nguyen, and Shiran Zhang

Citation: Review of Scientific Instruments 84, 034101 (2013); doi: 10.1063/1.4792673

View online: http://dx.doi.org/10.1063/1.4792673

View Table of Contents: http://scitation.aip.org/content/aip/journal/rsi/84/3?ver=pdfcov

Published by the AIP Publishing

\section{Articles you may be interested in}

The ReactorSTM: Atomically resolved scanning tunneling microscopy under high-pressure, high-temperature catalytic reaction conditions

Rev. Sci. Instrum. 85, 083703 (2014); 10.1063/1.4891811

A new scanning tunneling microscope reactor used for high-pressure and high-temperature catalysis studies

Rev. Sci. Instrum. 79, 084101 (2008); 10.1063/1.2960569

Evolution of the surface science of catalysis from single crystals to metal nanoparticles under pressure

J. Chem. Phys. 128, 182504 (2008); 10.1063/1.2888970

A high-pressure scanning tunneling microscope for studying heterogeneous catalysis

Rev. Sci. Instrum. 76, 023705 (2005); 10.1063/1.1841951

A high pressure, high temperature, scanning tunneling microscope for in situ studies of catalysts

Rev. Sci. Instrum. 71, 3777 (2000); 10.1063/1.1290043

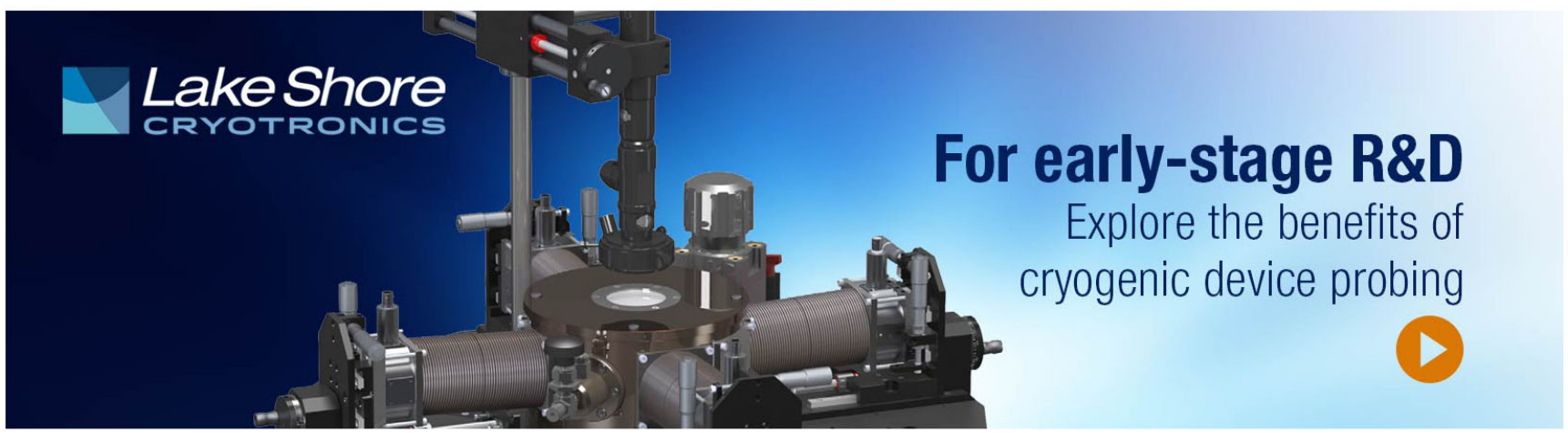




\title{
Design of a new reactor-like high temperature near ambient pressure scanning tunneling microscope for catalysis studies
}

\author{
Franklin (Feng) Tao, ${ }^{\text {a) }}$ Luan Nguyen, and Shiran Zhang \\ Department of Chemistry and Biochemistry, University of Notre Dame, Notre Dame, Indiana 46556, USA
}

(Received 14 December 2012; accepted 5 February 2013; published online 15 March 2013)

\begin{abstract}
Here, we present the design of a new reactor-like high-temperature near ambient pressure scanning tunneling microscope (HT-NAP-STM) for catalysis studies. This HT-NAP-STM was designed for exploration of structures of catalyst surfaces at atomic scale during catalysis or under reaction conditions. In this HT-NAP-STM, the minimized reactor with a volume of reactant gases of $\sim 10 \mathrm{ml}$ is thermally isolated from the STM room through a shielding dome installed between the reactor and STM room. An aperture on the dome was made to allow tip to approach to or retract from a catalyst surface in the reactor. This dome minimizes thermal diffusion from hot gas of the reactor to the STM room and thus remains STM head at a constant temperature near to room temperature, allowing observation of surface structures at atomic scale under reaction conditions or during catalysis with minimized thermal drift. The integrated quadrupole mass spectrometer can simultaneously measure products during visualization of surface structure of a catalyst. This synergy allows building an intrinsic correlation between surface structure and its catalytic performance. This correlation offers important insights for understanding of catalysis. Tests were done on graphite in ambient environment, $\operatorname{Pt}(111)$ in $\mathrm{CO}$, graphene on $\mathrm{Ru}(0001)$ in UHV at high temperature and gaseous environment at high temperature. Atom-resolved surface structure of graphene on $\mathrm{Ru}(0001)$ at $500 \mathrm{~K}$ in a gaseous environment of 25 Torr was identified. @ 2013 American Institute of Physics. [http://dx.doi.org/10.1063/1.4792673]
\end{abstract}

\section{INTRODUCTION}

Many chemical and physical processes are performed at interfaces of solid-liquid, or solid-gas such as thermal catalysis for chemical transformation and energy conversion, or at tri-phase zone of solid-liquid-gas for electrocatalysis in fuel cell and battery technology. Different from other physical or chemical processes, a solid catalyst must function in the environment of gas or/and liquid. In most cases, only a few atomic layers of surface and sub-surface play the role in catalysis. In contrast to atomic layers in a bulk, atoms of surface or/and subsurface typically exhibit different geometric structures due to their under-coordination when lattice is broken or distorted in surface region. Typically, these atoms relax to minimize their surface energy even in ultrahigh vacuum. The slight adjustment of atomic geometry and coordination is called surface relaxation. ${ }^{1}$ In addition, electronic state of atoms of surface is likely different since coordination environment of these atoms is different from that in bulk. In fact, an active catalyst surface is much more complicated when a surface is remained in an environment of gas or liquid. Atoms in surface layer and even nearly surface layers are significantly impacted by the existence of environment. ${ }^{2-6}$ The complexity is largely enhanced when the catalyst functions at a high temperature.

As reactant molecules are molecularly or dissociatively adsorbed on catalyst atoms of a surface, surface free energy is in fact influenced by the gas or liquid reservoir of adsorbed reactant molecules or species dissociated from reactant molecules. We can assume that a catalyst $\boldsymbol{A}$ is buried

\footnotetext{
a) Author to whom correspondence should be addressed. Electronic mail: ftao@nd.edu.
}

in a gaseous reactive environment such as $\boldsymbol{E}_{2}$ ( $\boldsymbol{E}$ is the element of a reactant gas). The catalyst surface is in a thermodynamic equilibrium with the gaseous environment. Under thermodynamic equilibrium, the surface is at equilibrium with the portion of catalyst atoms below the surface and the adsorbate molecules or species and gaseous molecules in gas reservoir (certain temperature and pressure) above it. The gaseous reservoir of adsorbate or dissociated species could influence the surface structure of catalysts. For example, gas reservoir with a high chemical potential could be favorable for a catalyst surface with high coverage of adsorbed molecules or dissociated species. The high coverage of adsorbates or dissociated species could restructure the catalyst surface correspondingly.

Therefore, in contrast to surface structure in ultra-high vacuum or high vacuum, the surfaces of catalysts in reactive or corrosive environments (reactive gases or liquids, acidic solutions, etc.) are very likely to restructure, in order to adapt their geometric and electronic structure to the surroundings. ${ }^{6-24}$ Such adaption induced from a gaseous or liquid environment could have profound effects on the functions of a catalyst. In many cases, the structure and composition of the catalyst surface in a reactive (or corrosive) environment in which it functions, differs from those in high vacuum. This difference has been demonstrated in recent studies. ${ }^{2,3,5}$

In addition, structure and chemistry of the catalyst surface upon removal of a catalytic or reaction condition could be different from that during catalysis since catalyst surface could be maintained only when the reactant mixture with certain pressure around the catalyst is remained at a high temperature. Figure 1 presents three potential surface phases of a catalyst upon removal of the catalytic condition after 


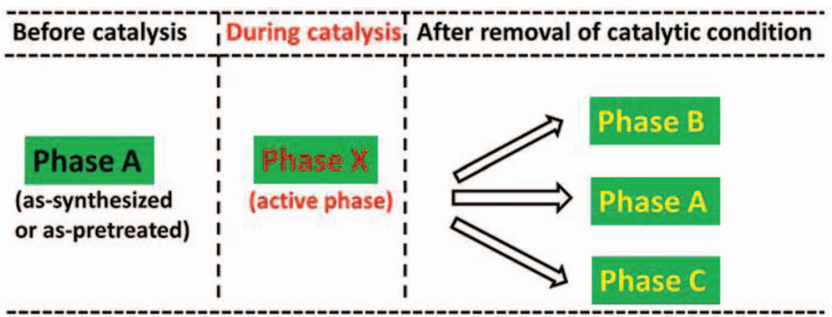

FIG. 1. Schematic showing three potential surface phases of catalysts upon removal of catalyst condition after catalysis.

catalysis. Thus, a characterization of a catalyst in high vacuum at room temperature or near to room temperature upon removal of the catalytic condition may not offer structure and chemistry of the original surface of catalyst during catalysis.

Recent studies have demonstrated that surface structure upon catalytic condition or reactive condition is removed could be different. One example is the pressure-dependent surface structure of a model catalyst $\operatorname{Pt}(557) .{ }^{9,20} \operatorname{Pt}(557)$ is restructured into nanoclusters with a thickness of 2-3 atomic layers under reaction condition (1 Torr $\mathrm{CO}$ or above). Interestingly, it reverts to a stepped surface after $\mathrm{CO}$ is purged and a high vacuum environment is reached. Another example is gas-dependent morphology of $\mathrm{Cu}$ nanoclusters on $\mathrm{ZnO}{ }^{11}$ Upon $\mathrm{H}_{2} \mathrm{O}$ of a mixture of $\mathrm{H}_{2}$ and $\mathrm{H}_{2} \mathrm{O}$ is purged, surface morphology is reverted to that in pure $\mathrm{H}_{2}$ environment. It is challenging to predict how an existing reactant gas environment could impact a catalyst surface during catalysis. One safe approach is to always track surface chemistry and structure during catalysis or under reaction conditions if techniques or instruments are available.

Vibrational spectroscopy has been used to track vibraitonal signature of adsorbates and even catalyst surfaces. ${ }^{25-28}$ scanning tunneling microscope (STM) is complimentary for vibrational spectroscopy since microscopy provides structural signature of the catalyst surface at atomic scale. However, operando study of surface structures of catalysts (surface coordination, atomic arrangement) at high temperature at atomic level has been an extremely challenging issue for many years.

STM itself can functionalize at ambient pressure conditions as the tunneling process occurs at a tip-sample junction with a distance of only $1 \AA-5 \AA$. Pressure does not prevent application of STM to catalysis. It has widely been used to image self-assembled monolayers at solid-liquid interfaces. ${ }^{29-33}$ In fact, filling gas into a UHV chamber with STM was the earliest version of high pressure STM studies. ${ }^{34}$ However, a direct filling of reactant gas in the whole UHV chamber certainly makes visualization in gaseous environment at high temperature and kinetics studies impossible due to reasons to be discussed in Sec. II A.

A few ambient pressure STMs or termed high pressure STMs were built. ${ }^{35-41}$ The possibility of performing STM studies was demonstrated in 1990s. ${ }^{35}$ Later, a high pressure STM with a relatively small volume of reaction cell was built. ${ }^{36,41}$ In addition, a chamber-based high pressure STM was designed by Besenbacher group. ${ }^{37} \mathrm{~A}$ highresolution Aarhus STM body was installed onto a UHV cham- ber through an 8 in. flange, ${ }^{37}$ in which reactant gas is directly filled into this chamber; Atom-resolved images of model catalyst at room temperature were obtained in reactant gases with different pressure. ${ }^{17}$ In addition, recently a high pressure cell with a volume of $1.5 \mathrm{~L}$ containing a STM head was built for studies in a pressure from UHV to 760 Torr. ${ }^{39}$ Most of these high pressure STMs are typically used to study surface structures of catalysts at room temperate in an environment of reactant/products at a pressure up to 1 bar. Recently, a chamberin-chamber high pressure STM was designed. ${ }^{40}$ In this design, the STM body including scanning tube and coarse approach motor, tip, and sample stage were installed into a small reactor with a free volume of only $19 \mathrm{~mL} .{ }^{40}$ It can visualize surface details of model catalysts at atomic level even up to ten bars at room temperature. In summary, progress was clearly made by several groups in this field; different high pressure STMs have been successfully built. These efforts have offered catalysis community new chemical information of model catalyst surface under reaction conditions and even during catalysis.

It has been noted that thermal drifts resulting from the non-equilibrium system of hot sample and cold tip and the decay stability of piezo-electrode at a varying temperature are barriers to achieve an image with atomic resolution from catalyst surface buried in a gaseous environment. Visualization of surface details at atomic level at a temperature higher than room temperature in gaseous environment of reactants has remained extremely challenging so far. This is the bottleneck to apply STM technique to identify surface details at atomic level during catalysis since most of catalysis is performed at a temperature higher than room temperature. To visualize surface structures of catalysts at high temperature in ambient pressure, here we designed a new reactorlike high-temperature near ambient pressure STM (HT-NAPSTM) through a collaboration with SPECS Surface Nano Analysis GbmH. Aarhus piezo scanning tube and coarse approaching motor were used. ${ }^{37}$ It was built at SPECS. In this HT-NAP-STM, catalytic reactor is separated from STM room and thus minimizes thermal drift, allowing visualizing surface structure at atomic level for catalyst surfaces at certain high temperature in near ambient pressure environment.

\section{DESIGN OF THE HIGH TEMPERATURE NEAR AMBIENT PRESSURE STM}

Figure 2(a) is a CAD drawing of the whole HT-NAPSTM system. Figure 2(b) is the photo of the whole HTNAP-STM system. It includes HT-NAP-STM chamber, sample preparation chamber, and a fast load lock. The feature of the new instrumentation of such a system is the integration of a minimized catalysis reactor and a STM room into a small cell called HT-NAP-STM cell here (Fig. 3). This cell is assembled to a regular UHV chamber (Fig. 2).

\section{A. Concept of a high temperature near ambient pressure STM cell with a differential pumping system}

Due to the factor of reaction temperature, it is necessary to have a reactor to separate the warm gas around a catalyst from the cold chamber wall. Without a reactor, large amount 


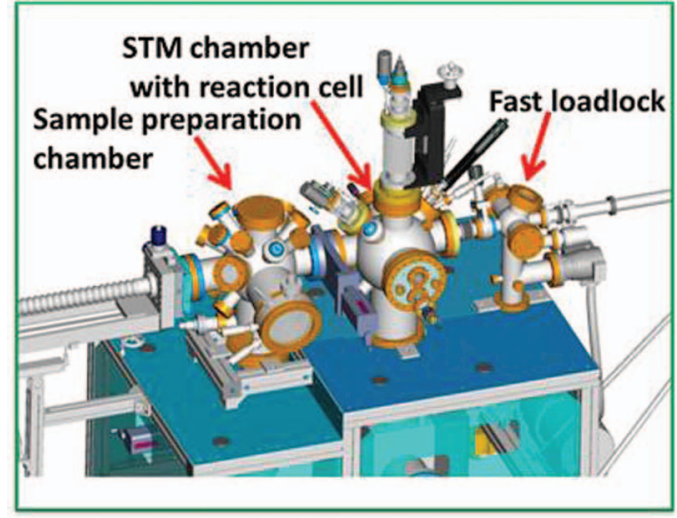

(a)

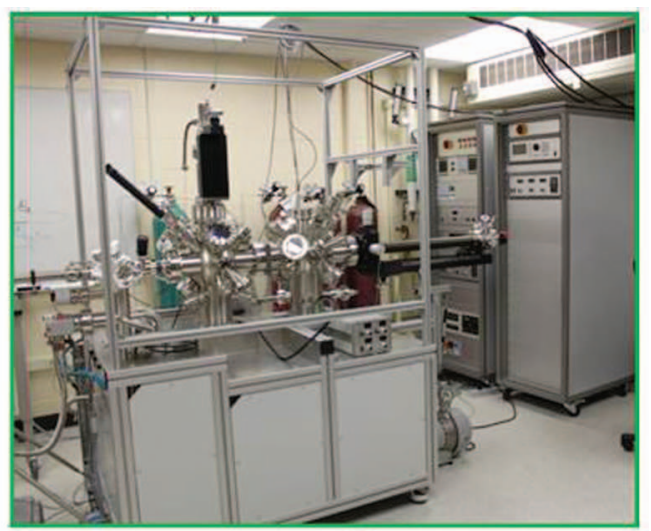

(b)

FIG. 2. Photo and CAD of HT-NAP-STM system in Tao group. (a) CAD drawing of the whole system (courtesy of SPECS Surface Nano Analysis GmbH). (b) Photo of the whole HT-NAP-STM system.

of heat is requested to maintain a sample at a relatively high temperature since the gas capacity in a regular UHV chamber is several or tens of liters which is much larger than $10 \mathrm{ml}$ of the reactor of this system. The gas in chamber will transfer a lot of heat from a hot catalyst to the chamber wall. A warm or hot chamber wall will desorb the adsorbed molecules such as $\mathrm{H}_{2} \mathrm{O}$ or contaminants which largely contaminate the catalyst surface during catalysis at high temperature. Without a reactor, the pressure of a reactant in a UHV chamber will be only 1 bar or lower since the sealing mechanism of a ConFlat flange of UHV chamber does not prevent leaking from cavity of a UHV chamber to ambient environment. In addition,

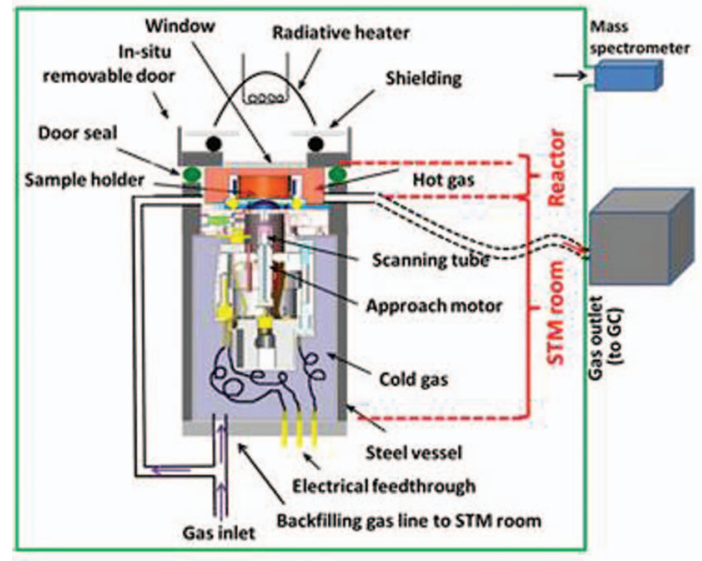

(a)

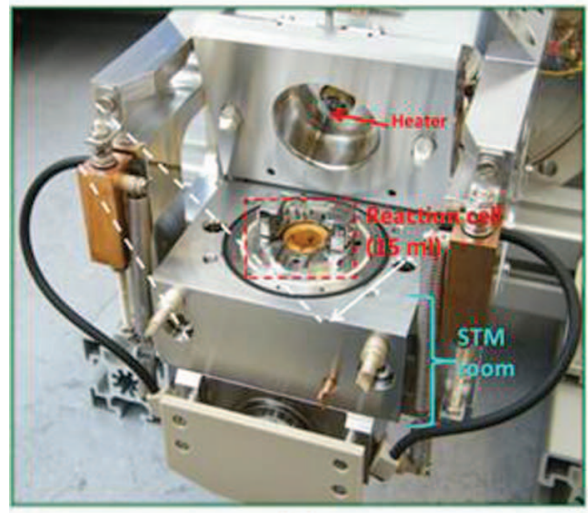

(c)

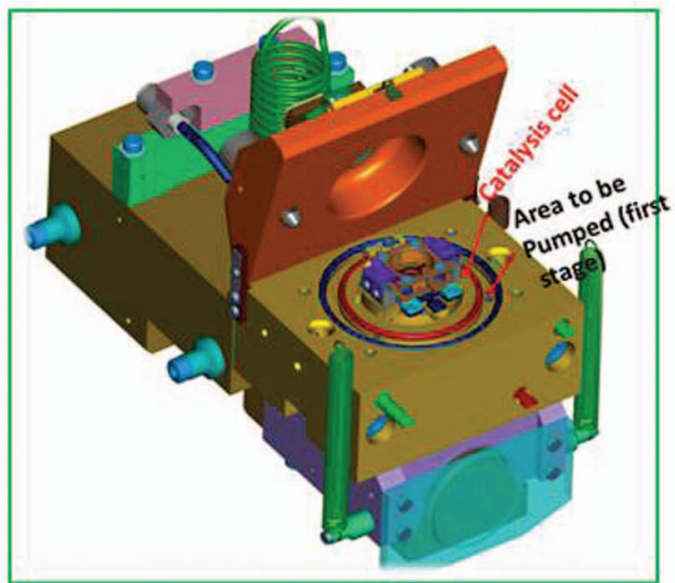

(b)

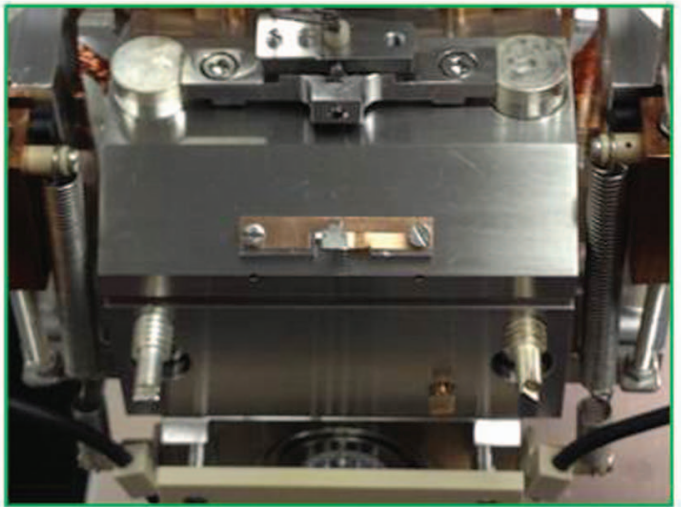

(d)

FIG. 3. Concept of catalysis reactor of HT-NAP-STM. (a) Schematic of building a flow reactor for simulating catalysis study. (b) CAD of the HT-NAP cell (courtesy of SPECS Surface Nano Analysis GmbH). (c) Photo of catalysis reactor when it is open to UHV environment. (d) Photo of catalysis reactor when gas is filled in the reactor. 


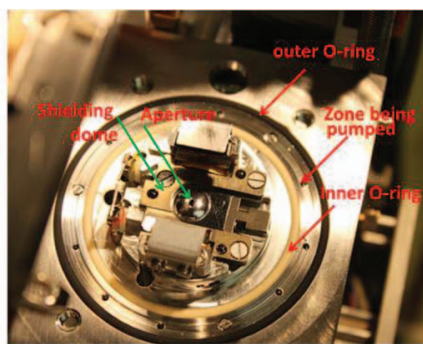

(a)

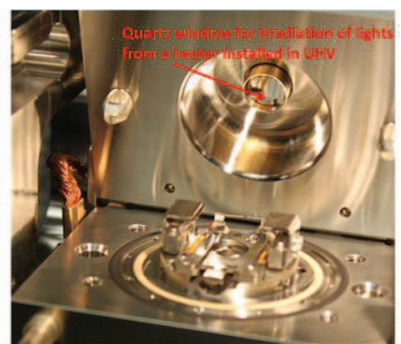

(b)
FIG. 4. Shielding dome and sample heating. (a) Shielding dome separating hot gas in catalysis reactor from STM room through an aperture for approaching and retracting tip. (b) Heating sample through irradiation from UHV to sample in a reactive environment.

to study surface during catalysis at kinetic control regime, the volume of a reactor should be 10-20 ml, similar to that of a micro-flow reactor used for evaluation of catalytic performances in most catalysis labs. However, in a single chamber design, where gas is filling in a whole UHV chamber, reactant gases are introduced into the chamber and kept in the chamber nearly statically. The mass transfer limitation resulting from a large amount of reactants around a catalyst in a UHV chamber makes kinetics studies impossible. Thus, it is challenging to simulate catalytic kinetics performed in a micro-flow reactor. Another reason is the vibration transduced from a UHV chamber to the STM room through the gaseous environment filling in the reactor.

In this HT-NAP-STM, we designed a minimized reactor for catalysis reactions. It can be run in a flow or batch mode (Fig. 3(a)). Different from other chamber-in-chamber design, ${ }^{40}$ here the minimized reactor was assembled to a STM room. More importantly, the STM room is thermally insulated from the reactor. The volume of gas filled in the reactor is only $\sim 10 \mathrm{ml}$. The hot gas filled in the reactor is marked with red in Fig. 3(a). Reactant gases are introduced through the inlet and flow out through the outlet. Figure 3(b) is the three-dimensional drawing of the reaction cell with differential pumping.

To have a better vacuum in the section between the reactor and the STM chamber wall to remain the cleanness of the STM chamber, it is necessary to minimize leaking of reactant gas from the reactor to the STM chamber. Thus, a differential pumping was designed (Fig. 4(a)). Using this differential pumping system, the vacuum in the UHV chamber can be remained at $10^{-8}$ Torr, while the pressure in the reaction cell is 100 Torr. Furthermore, the UHV chamber remains in an acceptable high vacuum even though the gas pressure in the reactor is 1 bar.

\section{B. Integration of a minimized reactor and STM room and minimization of thermal diffusion from the reactor to STM room}

As warm gas around a hot catalyst transfers energy to the STM room mainly including STM scanning tube and piezoelectric coarse approach motor, it is necessary to minimize thermal diffusion from warm gas to STM scanning tube and coarse approaching motor. A dome made of molybdenum
(Fig. 4(a)) to isolate the STM room from the reactor was installed. A small aperture of $0.5 \mathrm{~mm}$ was made at the center of the dome to allow tip approach to or retract from a catalyst surface. The small aperture largely reduced the flow of warm gas to STM head. In addition, a backfilling internal gas line was installed (Fig. 3(a)) to flow room-temperature reactant gases from STM room to the reactor through the aperture. This reverse flow of the same gas(es) at room temperature can counterbalance diffusion of warm or hot gas from catalysis reactor to STM room.

\section{Sample heating}

Catalyst in the reactor is heat by irradiation of catalyst surface from a halogen lamp through a window. The window is made as a part of the reactor (Fig. 4(b)). This lamp was installed at the vacuum side of the catalysis reactor. Sample temperature is measured through thermocouple attached to the sample in the reactor. Sample temperature is tuned through applying different power to the halogen lamp.

\section{Preservation of STM room at near room temperature}

Although piezo scanning tube and piezoelectric coarse approaching motor can be baked to $110^{\circ} \mathrm{C}$ for days, they only function at room temperature or near to room temperature $\left(<60{ }^{\circ} \mathrm{C}\right)$. It is necessary to remain them at a constant temperature during scanning. As described in Sec. II B the dome and its aperture and the backfilling gas line can effectively minimize the thermal exchange between hot catalysts and warm gases in catalytic reactor and STM room. Additionally, heating and cooling of the substrate of coarse approach motor and scanning tube help preserve a constant temperature during scanning. A $\mathrm{Cu}$ braid connected to the base of motor is used to cool the coarse approaching motor and thus further cool the scanning tube if the temperature of the coarse approaching motor and scanning tube is higher than the set temperature. Miniature Zener diode installed on the $\mathrm{Cu}$ block near to the STM motor can heat motor and scanning tube if the temperature of motor is lower than the set temperature. These instrumentations are critical for preservation of a constant temperature of STM room during scanning for a high resolution imagining when a sample is at high temperature in gaseous environment.

\section{E. Regeneration of a STM tip}

A fast exchange of STM tip is critical in the visualization of surfaces of catalysts during catalysis or under a reaction condition. As a tip could be contaminated readily in a gaseous environment, it needs to be replaced frequently for catalytic in situ and operando studies of catalysis in contrast to UHV-STM studies. A convenient preparation of a refresh tip is necessary. In this HT-NAP-STM, an in situ regeneration method is applied. A sputter ion gun installed on a manipulator of STM chamber (Fig. 2(b)) is used to regenerate a new tip. The Ar ion beam will mill the tip materials. The rate of 


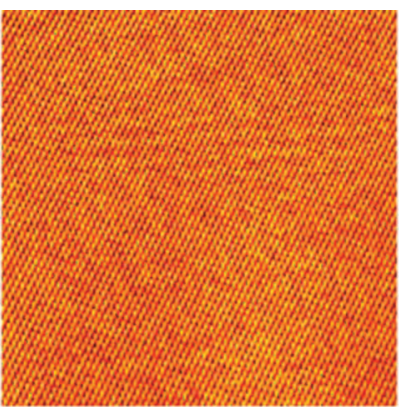

(a)

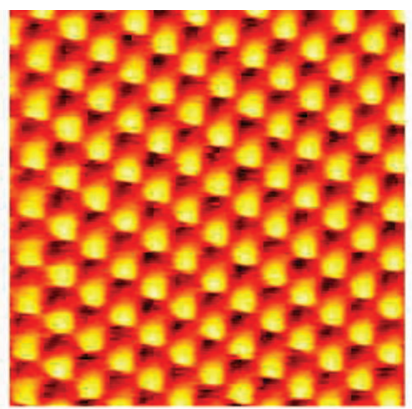

(b)
FIG. 5. STM image of HOPG collected in air. (a) $200 \AA \times 200 \AA$. (b) $25 \AA \times 25 \AA$.

shoveling off tip materials (W or Pt-Ir) at the edge of a round wire is much larger than that at the center of a metal wire. An ion source is installed right above the cover of the catalytic reactor. Thus, a sputtering of a used tip for 5-10 min can regenerate a fresh tip without a replacement of tip.

\section{VISUALIZATION OF CATALYST SURFACE BY USING THIS HT-NAP-STM}

We tested this HT-NAP-STM system with different samples in different environments at different temperatures including HOPG at room temperature in air, graphene on $\mathrm{Ru}(0001)$ at high temperature in vacuum, $\mathrm{Pt}(111)$ at room temperate in $\mathrm{CO}$ remained in catalysis reactor, graphene on $\mathrm{Ru}(0001)$ at high temperature in $\mathrm{N}_{2}$ remained in catalysis reactor. Figure 5 is atom-resolved images of HOPG in ambient environment at $25{ }^{\circ} \mathrm{C}$. Obviously, every other carbon atom of the surface layer of HOPG is clearly resolved.

Graphene was grown on $\mathrm{Ru}(0001)$ substrate in the STM chamber. To test the high temperature function in UHV, STM images were collected when graphene on $\mathrm{Ru}(0001)$ was remained at $700 \mathrm{~K}$. Figure 6 is the images of graphene grown on $\mathrm{Ru}(0001)$ which were collected when sample was at $700 \mathrm{~K}$ in UHV. Moire pattern was obvious on this surface (Fig. 6(a)). $\mathrm{O}(2 \times 2)$ superstructure formed at step edge of $\mathrm{Ru}(0001)$ marked with a rectangle box was clearly identified at $700 \mathrm{~K}$ (Fig. 6(a)). Notably, each carbon atom of the graphene layer
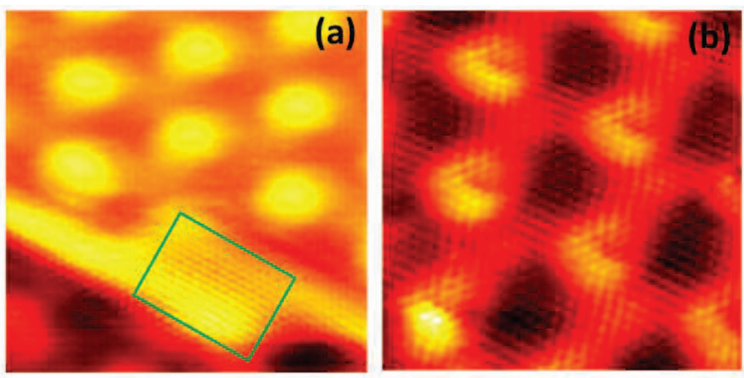

FIG. 6. STM images of graphene grown on $\mathrm{Ru}(0001)$. Both images were collected when sample was at $700 \mathrm{~K}$ in UHV. (a) $100 \AA \times 100 \AA$. The large spots form a Moire pattern. The area marked with a rectangle box is $\mathrm{O}(2 \times 2)$ formed at step edge of $\mathrm{Ru}(0001)$. (b) $74 \AA \times 74 \AA$. The large, bright feature forms the Moire pattern. Each bright spot in (b) is one carbon atom of graphene grown on $\mathrm{Ru}(0001)$. (Courtesy of SPECS Surface Nano Analysis GmbH.)

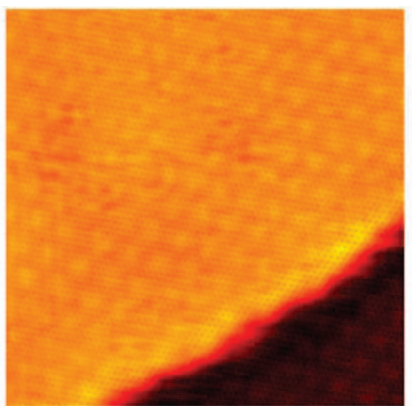

(a)

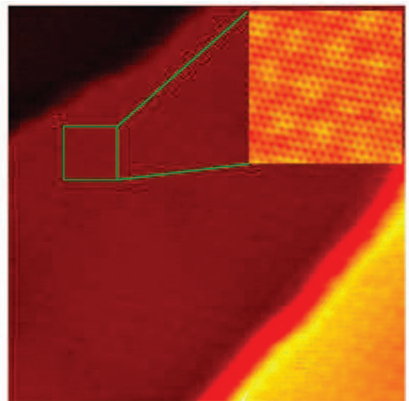

(b)
FIG. 7. STM images of model catalyst $\mathrm{Pt}(111)$ in 1 Torr $\mathrm{CO}$ at room temperature. (a) $150 \AA \times 150 \AA$. (b) $250 \AA \times 250 \AA$; size of inset: $40 \AA ̊ \times 40 \AA$.

on $\mathrm{Ru}(0001)$ was clearly visualized when surface is at $700 \mathrm{~K}$ in UHV (Fig. 6(b)). These tests demonstrated the function of visualization of surface at atomic scale when the sample is at high temperature in UHV.

In order to test the function of the reaction cell at room temperature, $\mathrm{Pt}(111)$ was installed as as a model catalyst. $\mathrm{CO}$ gas was introduced to the flow cell; $\mathrm{CO}$ pressure in the reactor is kept at 1 Torr. This HT-NAP-STM was used to examine $\mathrm{Pt}(111)$ surface at room temperature in CO. In Fig. 7, terraces and edges were clearly identified. Moire pattern was observed. It is similar to early observation. ${ }^{17}$ Atomic details of the $\mathrm{Pt}(111)$ surface in gaseous environment of $\mathrm{CO}$ were clearly identified in the inset of Fig. 7(b).

The HT-NAP-STM was used for visualization of surface of graphene on $\mathrm{Ru}(0001)$ when the surface was at $500 \mathrm{~K}$ in 25 Torr $\mathrm{N}_{2}$. Notably, the scanning was being performed when the sample was at $500 \mathrm{~K}$ in 25 Torr nitrogen. This is the way to observe surface structure of model catalyst during catalysis. Moire pattern was clearly observed in Fig. 8(a). Scanning a small area offered information on carbon atoms of graphene layer on $\mathrm{Ru}(0001)$. Carbon atoms of the graphene layer grown on $\mathrm{Ru}(0001)$ were real-time identified when the sample was at $500 \mathrm{~K}$ in 25 Torr $\mathrm{N}_{2}$. These tests confirmed the success of imaging surface of catalysts with atomic resolution at high temperature with near ambient pressure.

Another feature of the application of this HT-NAP-STM is to track the dynamic restructuring of model catalysts with the fast scan mode. As shown in Fig. 9, restructuring was
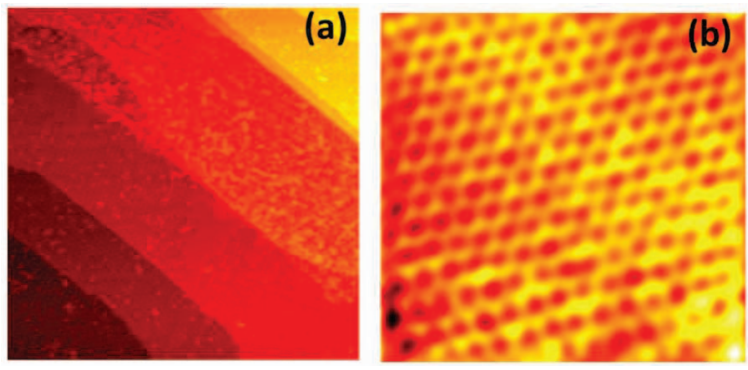

FIG. 8. STM images of graphene grown on $\mathrm{Ru}(0001)$. These images were taken when sample was at $500 \mathrm{~K}$ in 25 Torr $\mathrm{N}_{2}$ gas. (a) Large scale image of graphene on $\mathrm{Ru}(0001)$ : $1700 \AA \times 1700 \AA$. Bright spots form Moire pattern. (b) Atom-resolved image of graphene at $500 \mathrm{~K}$ in 25 Torr $\mathrm{N}_{2}$ gas. (Courtesy of SPECS Surface Nano Analysis GmbH.) 


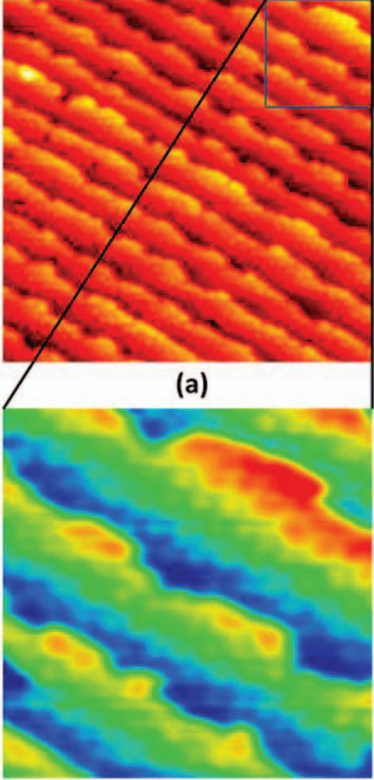

(c)

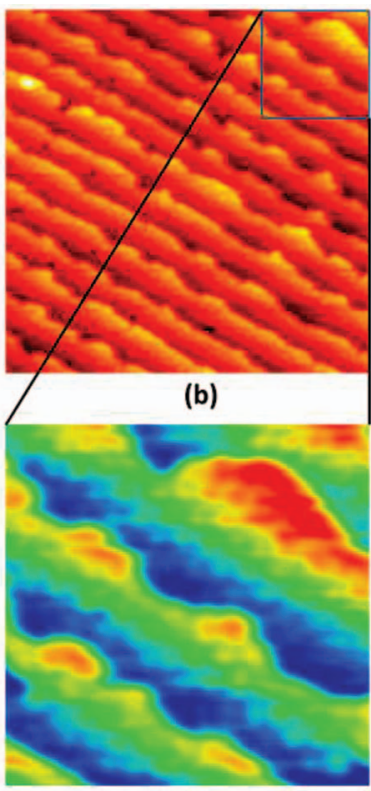

(d)
FIG. 9. Time-dependent restructuring of atoms at edge of $\mathrm{Pt}(111)$ terraces in 20 Torr $\mathrm{CO}$ at room temperature. (a) $\mathrm{Pt}(111)$ in 20 Torr $\mathrm{CO}$ at time to; size: $430 \AA \times 430 \AA$. (b) Same area of $\mathrm{Pt}(111)$ as that in (a) in 20 Torr CO at time to+ $1 \mathrm{~min}$; size: $430 \AA \times 430 \AA$. (c) Enlargement of structural feature at to; $130 \AA \times 130 \AA$. (d) Enlargement of structural feature of the same area as (c) at to $+1 \mathrm{~min} ; 130 \AA \times 130 \AA$. A comparison between (c) and (d) clearly showed the formation of Pt nanoclusters at edge of terraces within $1 \mathrm{~min}$.

clearly identified. Nanoclusters are formed at edge of terraces with a timescale of $1 \mathrm{~min}$. Figure 9 demonstrated the function of tracking restructuring of atoms of model catalysts at a timescale of seconds to minutes. ${ }^{42}$

\section{CONCLUSIONS}

Driven by the necessity of studying surface structure of catalysts at atomic level during catalysis or under reaction conditions, a new high temperature near ambient pressure STM (HT-NAP-STM) was successfully designed. The main feature is the successful separation of reaction cell from STM room by installation of a dome with an aperture for tip moving in or out. Visualization of surface structures of catalysts at high temperature in near ambient pressure at atomic level was demonstrated for the first time. The reactor-like HT-NAPSTM allow to measure catalytic performances during catalysis in a flow reactor and simultaneously visualize the surface structure of a catalyst at atomic level, building a correlation between surface structure and catalytic performance of this catalyst. Such a correlation is critical in understanding catalytic mechanism.

\section{ACKNOWLEDGMENTS}

This work was partially supported by the Chemical Sciences, Geosciences and Biosciences Division, Office of Basic Energy Sciences, Office of Science, U.S. Department of Energy under Grant No. DE-FG02-12ER1635, and University of Notre Dame.
F.T. appreciates the collaboration with SPECS Nano Surface Analysis $\mathrm{GmbH}$ in developing and building this instrument.

This paper was read by Dr. Oliver Schaff, Dr. Stefan Schmitt, and Dr. Andreas Thissen of SPECS Nano Surface Analysis $\mathrm{GmbH}$ before submission. They understood and agreed this was a collaboration between Tao group and SPECS in making this first high temperature near ambient pressure STM of SPECS Nano Surface Analysis GmbH.

${ }^{1}$ G. A. Somorjai and Y. Li, Introduction to Surface Chemistry and Catalysis, 2nd ed. (Wiley, Hoboken, NJ, 2010).

${ }^{2}$ F. F. Tao and M. Salmeron, Science 331, 171 (2011).

${ }^{3}$ F. F. Tao, S. Zhang, L.Nguyen, and X. Zhang, Chem. Soc. Rev. 41, 7980 (2012).

${ }^{4}$ C. W. Jones, F. F. Tao, and M. V. Garland, ACS Catal. 2, 2444 (2012).

${ }^{5}$ F. F. Tao, Chem. Soc. Rev. 41, 7977 (2012).

${ }^{6}$ H. Yoshida, Y. Kuwauchi, J. R. Jinschek, K. Sun, S. Tanaka, M. Kohyama, S. Shimada, M. Haruta, and S. Takeda, Science 335, 317 (2012).

${ }^{7}$ F. Tao, M. E. Grass, Y. W. Zhang, D. R. Butcher, J. R. Renzas, Z. Liu, J. Y. Chung, B. S. Mun, M. Salmeron, and G. A. Somorjai, Science 322, 932 (2008).

${ }^{8}$ F. Tao, M. E. Grass, Y. W. Zhang, D. R. Butcher, F. Aksoy, S. Aloni, V. Altoe, S. Alayoglu, J. R. Renzas, C. K. Tsung, Z. W. Zhu, Z. Liu, M. Salmeron, and G. A. Somorjai, J. Am. Chem. Soc. 132, 8697 (2010).

${ }^{9}$ F. Tao, S. Dag, L.-W. Wang, Z. Liu, D. R. Butcher, H. Bluhm, M. Salmeron, and G. A. Somorjai, Science 327, 850 (2010).

${ }^{10}$ T. W. Hansen, J. B. Wagner, P. L. Hansen, S. Dahl, H. Topsoe, and C. J. H. Jacobsen, Science 294, 1508 (2001).

${ }^{11}$ P. L. Hansen, J. B. Wagner, S. Helveg, J. R. Rostrup-Nielsen, B. S. Clausen, and H. Topsoe, Science 295, 2053 (2002).

${ }^{12}$ S. Helveg, C. Lopez-Cartes, J. Sehested, P. L. Hansen, B. S. Clausen, J. R. Rostrup-Nielsen, F. Abild-Pedersen, and J. K. Norskov, Nature (London) 427, 426 (2004).

${ }^{13}$ F. M. F. de Groot, E. de Smit, I. Swart, J. F. Creemer, G. H. Hoveling, M. K. Gilles, T. Tyliszczak, P. J. Kooyman, H. W. Zandbergen, C. Morin, and B. M. Weckhuysen, Nature (London) 456, 222 (2008).

${ }^{14}$ R. Wang, P. A. Crozier, R. Sharma, and J. B. Adams, Nano Lett. 8, 962 (2008).

${ }^{15}$ Z. T. Zhu, F. F. Zheng, R. Chang, Y. Li, L. Heinke, Z. Liu, M. Salmeron, and G. A. Somorjai, Nano Lett. 12, 1491 (2012).

${ }^{16}$ G. Ketteler, D. F. Ogletree, H. Bluhm, H. J. Liu, E. L. D. Hebenstreit, and M. Salmeron, J. Am. Chem. Soc. 127, 18269 (2005).

${ }^{17}$ S. R. Longwitz, J. Schnadt, E. K. Vestergaard, R. T. Vang, E. Laegsgaard, I. Stensgaard, H. Brune, and F. Besenbacher, J. Phys. Chem. B 108, 14497 (2004).

${ }^{18}$ B. L. M. Hendriksen and J. W. M. Frenken, Phys. Rev. Lett. 89, 046101 (2002).

${ }^{19}$ C. Wen, Y. Liu, and F. Tao, Pure Appl. Chem. 83, 243 (2011).

${ }^{20}$ M. S. Altman, Science 327, 789 (2010).

${ }^{21}$ M. Salmeron and R. Schlogl, Surf. Sci. Rep. 63, 169 (2008).

${ }^{22}$ F. Tao, Chem. Commun. 48, 3812 (2012).

${ }^{23}$ Y. Zhu, Y. Ye, X. Zhang, L. Wang, W. Zhu, F. Cheng, and F. F. Tao, ACS Catal. 2, 2403 (2012).

${ }^{24}$ C. Wen, Y. Zhu, Y. Ye, S. Zhang, F. Cheng, Y. Liu, P. Wang, and F. Tao, ACS Nano 6, 9305 (2012).

${ }^{25}$ P. C. Stair, Curr. Opin. Solid State Mater. Sci. 5, 365 (2001).

${ }^{26}$ S. Alayoglu, J. M. Krier, W. D. Michalak, Z. Zhu, E. Gross, and G. A. Somorjai, ACS Catal. 2, 2250 (2012).

${ }^{27}$ G. A. Somorjai, Chem. Soc. Rev. 13, 321 (1984).

${ }^{28}$ G. A. Somorjai and J. Y. Park, Chem. Soc. Rev. 37, 2155 (2008).

${ }^{29}$ S.-S. Li, B. H. Northrop, Q.-H. Yuan, L.-J. Wan, and P. J. Stang, Acc. Chem. Res. 42, 249 (2009).

${ }^{30}$ L. C. Giancarlo and G. W. Flynn, Acc. Chem. Res. 33, 491 (2000).

${ }^{31}$ F. Tao and S. L. Bernasek, J. Am. Chem. Soc. 127, 12750 (2005).

${ }^{32}$ F. Tao and S. L. Bernasek, Chem. Rev. 107, 1408 (2007).

${ }^{33}$ F. Tao, Pure Appl. Chem. 80, 45 (2008).

${ }^{34}$ B. J. McIntyre, M. B. Salmeron, and G. A. Somorjai, Catal. Lett. 14, 263 (1992). 
${ }^{35}$ B. J. McIntyre, M. Salmeron, and G. A. Somorjai, Rev. Sci. Instrum. 64, 687 (1993).

${ }^{36}$ P. B. Rasmussen, B. L. M. Hendriksen, H. Zeijlemaker, H. G. Ficke, and J. W. M. Frenken, Rev. Sci. Instrum. 69, 3879 (1998).

${ }^{37}$ E. Laegsgaard, L. Osterlund, P. Thostrup, P. B. Rasmussen, I. Stensgaard, and F. Besenbacher, Rev. Sci. Instrum. 72, 3537 (2001).

${ }^{38}$ L. Petersen, M. Schunack, B. Schaefer, T. R. Linderoth, P. B. Rasmussen, P. T. Sprunger, E. Laegsgaard, I. Stensgaard, and F. Besenbacher, Rev. Sci. Instrum. 72, 1438 (2001).
${ }^{39}$ M. Rossler, P. Geng, and J. Wintterlin, Rev. Sci. Instrum. 76, 023705 (2005).

${ }^{40}$ F. Tao, D. Tang, M. Salmeron, and G. A. Somorjai, Rev. Sci. Instrum. 79, 084101 (2008).

${ }^{41}$ R. van Rijn, M. D. Ackermann, O. Balmes, T. Dufrane, A. Geluk, H. Gonzalez, H. Isern, E. de Kuyper, L. Petit, V. A. Sole, D. Wermeille, R. Felici, and J. W. M. Frenken, Rev. Sci. Instrum. 81, 014101 (2010).

${ }^{42}$ L. Nguyen, F. Cheng, S. Zhang, and F. Tao, J. Phys. Chem. C 117, 971 (2013). 